\title{
EHEALTH EUROCAMPUS: AN INNOVATIVE EDUCATIONAL FRAMEWORK TO TRAIN QUALIFIED PROFESSIONALS IN THE EMERGING EHEALTH SECTOR
}

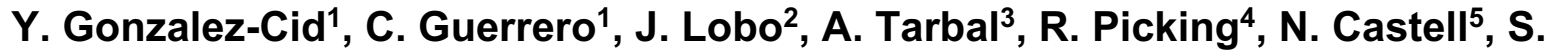

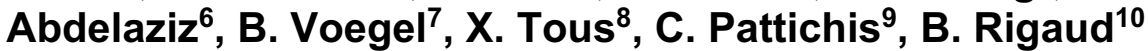 \\ ${ }^{1}$ Universitat de les IIles Balears (SPAIN) \\ ${ }^{2}$ Eurorégion Pyrénées-Méditerranée GECT (FRANCE) \\ ${ }^{3}$ Fundació Sant Joan de Déu (SPAIN) \\ ${ }^{4}$ Wrexham Glyndwr University (UNITED KINGDOM) \\ ${ }^{5}$ Universitat Politècnica de Catalunya (SPAIN) \\ ${ }^{6}$ Université de Montpellier (FRANCE) \\ ${ }^{7}$ Hochschule Ulm (GERMANY) \\ ${ }^{8}$ Fundació Bit (SPAIN) \\ ${ }^{9}$ University of Cyprus (CYPRUS) \\ ${ }^{10}$ Institut National Universitaire Champollion (FRANCE)
}

\begin{abstract}
The aim of this paper is to present the results of an initiative called the eHealth Eurocampus (http://ehealtheurocampus.eu), whose main goal is to define a framework to prepare professionals for the eHealth work environment. To do so, three main activities have been organized: develop eHealth learning materials, international intensive study programs for both health science and IT students and international training seminars for researches and professors.

The consortium of the eHealth Eurocampus project along with the participants of the designed activities have created an original eHealth teaching-learning framework where university professors, students, researchers, and clinicians are able to share their experiences and knowledge with the aim of improving the skills of graduates in order to improve their employability.
\end{abstract}

All the materials and experiences are shared and available to all the stakeholders at ehealtheurocampus.eu

Keywords: EHealth, multidisciplinary teaching, international cooperation, innovation in education.

\section{INTRODUCTION}

The eHealth Eurocampus project [1] is an EU-funded Erasmus+ Strategic Partnership for higher education (September-2016 / August-2019) which aims at preparing qualified professionals able to cope with the challenge of "fostering a spirit of innovation in eHealth in Europe as the way forward to ensure better health and better and safer care for EU citizens, a more skilled workforce, more efficient and sustainable health and care systems, new business opportunities" (EC eHealth Action Plan 2012-2020).

The consortium of this project includes 8 higher education institutions, which represent 7 IT schools (Barcelona School of Informatics - UPC, Higher Polytechnic School of the University of the Balearic Islands - UIB, Polytech Engineer School of Montpellier - UM, ISIS Engineering School of Castres - ISIS, Glyndwr University of Wales - WGU, Hochschule UIm - HSU, and the Department of Computer Science of the University of Cyprus - UCY) and 3 medical schools (Faculty of Nursing and Physiotherapy of the University of the Balearic Islands - UIB , Medical School of Cyprus - UCY, Sant Joan de Déu University School of Nursing - Barcelona - FSJD), a regional centre of technological development and entrepreneurship promotion (Bit Foundation of Mallorca - FBIT), and a European Grouping of Territorial Cooperation (EGTC Pyrenees-Mediterranean).

The term eHealth was barely used before 1999. The term was apparently first used by industry leaders and marketing people rather than academics and was defined at the beginning of the current century [2][3]. However, eHealth is still an emerging domain, both in academia and industry [4] [5] [6]. 
In this paper, we introduce in detail the different activities carried out in the context of the eHealth Eurocampus project and the results of this teaching-learning innovative framework and how the different stakeholders would take advantage of it.

\section{METHODOLOGY}

The consortium of the eHealth Eurocampus project along with the participants of the designed activities have created an original eHealth teaching-learning framework where university professors, students, researchers, and clinicians are able to share their experiences and knowledge with the aim of improving the skills of graduates in order to improve their employability.

These are the organized activities and the topics that have been covered:

- eHealth learning materials. Five courses of 6 ECTS each have been developed in the following topics: innovation and entrepreneurship, IT for a longer independent life, robotics for health care, graphics and medical imaging and eHealth applications and tools.

- Intensive study programs. Three international summer schools for both health and IT students have been organized with an interdisciplinary approach. The first one deal with innovation and entrepreneurship in eHealth. The second one is focused on applications and tools for longer independent life. And robotics, graphics and medical imaging are covered in the third one. The summer schools have proven to be the best testbed for the learning materials and for innovative teaching methodologies in interdisciplinary context.

- Training seminars. When you face the training of qualified eHealth professionals it is critical to have good educators. Two training seminars have been organized with the goal of share experiences and knowledge among practitioners, university teachers and researches of the health and IT fields. The topics covered in the seminars are eHealth Teaching Challenges and Accessibility, Inclusion, and Rehabilitation using IT, respectively.

\section{1 eHealth learning materials}

Five different courses of 6 ECTS have been designed and developed. One of the partners of the consortium has been the coordinator of each course while the rest of the partners support the creation of the teaching-learning materials. All the courses have been created in three steps: production, review and evaluation.

During these three steps the learning materials are hosted in a private area using the Moodle platform. Each course has its corresponding Moodle course in order to administrate and to monitor the development of the module. The Moodle courses are not supposed to be used by the final users, but they aim to support teachers and collaborators to understand the structure of the courses, and which materials are appropriate.

The review is made by all the partners involved in the development of the courses and the evaluation is done in an Intensive Study Program for students in summer school format (see subsection 2.2). After each summer school the educational material is again revised taking into account the experience of the summer school and the feedback of the students and teachers. This last version is again reviewed now by an expert who might recommend some changes or improvements.

Once the final version of the educational material of each course is ready it will be available for the public use from the web page of the project (http://ehealtheurocampus.eu).

All the courses will offer a teacher's guide and a set of slides, where some of which have teacher's guidance notes in the Notes section. The slides provide theoretical content as well as examples, exercises and case studies. A suggested reading list is also available for each course.

These are the main 5 topics of the courses that have been developed:

- innovation and entrepreneurship

- IT for a Longer Independent Life

- eHealth Applications and Tools

- Robotics for Healthcare

- Graphics and Medical Imaging 
The courses are designed for students who have almost finished their bachelor's degree or who are doing their master's course. They should be accessible to a wide range of student specialisms, including computing, clinical, business, design, and engineering subjects.

For each lesson or content of the courses, it will be provided:

- Guidelines for teaching: slides comments, explanations, examples... to give support to teachers that have to explain the contents.

- A schedule or timetable, including a detailed distribution of working hours.

- Complementary study materials (book chapters, papers, solved exercises, videos, ...).

- Exercises that have to be done by the students, with instructions and guidelines.

\subsubsection{Course 1: Innovation and Entrepreneurship}

Innovation is a main driver of enterprise's competitiveness and economic growth. Western countries showing the highest rate of economic development are those in which enterprise birth rate is also the higher. In westerns countries, there is a strong correlation between job growth and the creation of new businesses, that is with new entrepreneurs.

In France the rate of young people aged between 18 and 25 years who express the desire for creating an enterprise has been growing for more a decade [7]. Their ability to adapt to the new digital economy and to comply with a certain professional nomadism make these students key actors to prepare the jobs of tomorrow, which $50 \%$ of them will be invented in the next 10 years. Young IT engineers, as future actors of economic growth, have a social responsibility: creating sustainable jobs and businesses.

This course introduces students to entrepreneurship, giving positive images of businessmen, and encouraging them to creation and innovation through "action training" approaches.

This is the table of contents of this course:

Chapter I. Introduction

Chapter II. Innovation in eHealth

European trends: social including social and health challenges in medium and long terms

Strategic digital and technological trends

Innovation in eHealth: dynamics and obstacles

Examples of health innovation models and tangibles examples of innovative product and services

Open Innovation in eHealth

Initiation workshops on open innovation in eHealth

Chapter III. Ethical Issues in eHealth

Ethical issues in eHealth

Robotics in eHealth

Innovation workshop \& short presentation

Chapter IV. The Entrepreneurship Process

Introduction to the entrepreneurship process

Building the founding team

The process of designing a business model: introduction

Opportunity recognition and business validation

The process of designing a business model: creativity techniques

Understanding your business model and developing strategy

Business planning

Business model validation

Entrepreneurial marketing

Building your pro forma financial statements

Raising money for starting and growing businesses

Examples of use cases for teamwork(brainstorming)

Teaching approaches to student entrepreneurship

\subsubsection{Course 2: IT for a Longer Independent Life}

The overall aim of this module is to develop students' skills in designing software applications to support a longer independent life for their users. 
At the end of this module, students will (1) possess the knowledge and skills to produce high-quality prototype designs that can subsequently be tested with users in a controlled environment, such as a usability laboratory and (2) gain the appropriate skills to design field testing (in real-world environments).

There are 5 chapters each representing approximately 10 blocks of 90 minutes teaching, making a total of 15 hours ( +1 for contingencies). Therefore, there is a total of 80 hours teaching activity for this course ( +75 hours of independent study). Below you can find the table of contents of this course:

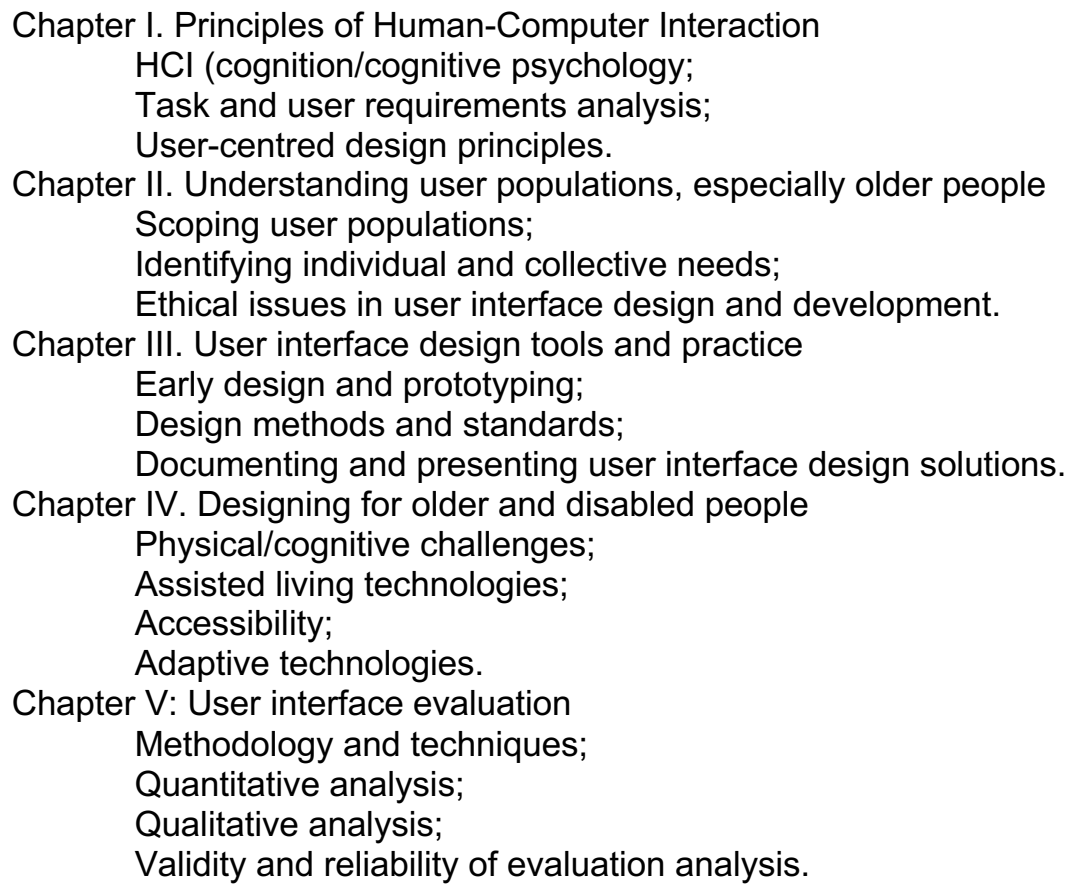

After finishing the course, two assessments are proposed: one is an app design exercise and the other is a usability evaluation plan. They could be weighted at $50 \%$ each for the overall module assessment. For instances, assessment 1 could be designing an app for a clinical need to solve a problem in the domain of supporting independent living for older and/or disabled people, using an appropriate design tool (e.g. Marvelapp) and assessment 2 could be writing a usability evaluation plan that could be used to test the fully developed app in an appropriate real-world setting. It would not be necessary to develop the app itself.

\subsubsection{Course 3: eHealth Applications and Tools}

The overall aim of this course is to develop students' skills in designing software, mainly mobile applications to enable patients and elder persons to live longer independently and to collect medical parameter data in order to monitor the patient or to provide telemedical treatment.

To take this course it is highly recommended that the students know the programming language Java and basics in database design.

This module contains the means and tools to develop mobile application in the context of eHealth. At the end of the module, the students know how to design apps, how to process internal and external sensors, how to deploy apps common standards in communication, especially HL7 FHIR, how to analyze data and how to protect data privacy which legal and ethical questions have to be considered.

Below you can find the table of contents of this course:

Chapter I. Introduction

General overview of course content and a basic understanding of the term/concept eHealth in this module.

Chapter II. Current Situation

This chapter introduces the current techniques and standards. It enlights the possibilities in developing a mobile app. It includes a guide on how to validate an app as a regulated medical device.

Chapter III. App Development Part 1 
General overview and first steps in App-Development. Further topics are basics about $\mathrm{UI}$ and the connection to internal sensors

Chapter IV. Communication Server \& Messages

Different institutions in the health content have to exchange data of persons/patients. Quite often this not done directly, peer to peer, normally the exchange is done with a communication server/integration engine. In health there is a very well-established organization to develop message standards - HL7 (Health Level 7). In this chapter the basics of messages and the different versions of $\mathrm{HL} 7$ will be introduced. Furthermore, the functionality of an integration engine will be demonstrated on base of Nextgen Connect (former Mirth Connect).

Chapter V. FHIR Details/Server + Tools

HL7 FHIR is the future of messages in Healthcare, mainly in mobile applications. FHIR will be intensively introduced and there will be a detailed look on the corresponding software products

Chapter VI. DB Techniques

Basic repetition of DB and SQL and introduction to approaches of data analysis

Chapter VII: App Development II

Deeper knowledge of App developing and connection to external sensors/devices.

Chapter VIII. Ethics and juridical aspects

Chapter IX: Privacy and Data Security

This course could be assessed by a written exam about the theory and a group project work to develop a mobile app. The suggested weight of each part is $30 \%$ and $70 \%$ respectively.

\subsubsection{Course 4: Robotics for Healthcare}

This module aims at providing skills and knowledge on robotics and their application in healthcare.

Problem based learning and working in multidisciplinary groups methodologies are used in order to achieve a wide and deep knowledge about the use of robot technologies in healthcare.

The main goals of the course are the introduction to the methodological bases of robot modelling and control as well as the analysis of the medical requirements of robotics in each health area.

By the end of the course, the student should have skills and knowledge to consider the human factors as part of the inputs to the project to develop; Analyze a problem and identify the project requirements; Select the adequate control strategy for each robot project; Conceive a project as a whole; Develop project in the field of systems engineering, control and robotics for healthcare.

Below you can find the table of contents of this course:

Chapter I. Foundation of robotics.

Robot components. Robot's morphology, Kinematics, Dynamics and Control. Robot architecture and applications.

Chapter II. Human robot interaction in medical robotics.

Teleoperation. Cooperation. Shared control. Haptic devices.

Chapter III. Assistive robotics.

Technology to help elder and handicapped people. Robots for mobility. Robots at home.

Chapter IV. Rehabilitation robotics.

Robots to support the rehabilitation practitioner. Active FES technology. Exoskeleton. Dealing with physical and cognitive disabilities.

Chapter V. Prosthesis.

Lower extremity. Arm and Hands. Technologies for partial or total blindness and hearing

Chapter VI. Surgical robotics.

Teleoperated and autonomous systems, Laparoscopic surgery. Neurosurgery. Nano robots.

This module is conceived using a Project Based Learning (PBL) approach. The creation of multidisciplinary student groups will be promoted in order to address these projects.

The course consists of several theoretical and practical units, accompanied with the development of 2 or 3 projects. In each practical case, students will have to analyze medical requirements and decide about the suitable technologies to be used in each case. These works will be the main component for course assessment. 


\subsubsection{Course 5: Graphics and Medical Imaging}

This module will be delivered in three different parts and will cover, 1 ) the fundamental components of medical image analysis and visualization, 2) virtual environments and advanced computer graphics and 3) game design and serious games involved. It will develop skills (graphics) that make students operative regarding health applications to cope with physical and cognitive disabilities.

The course will cover basic knowhow, and technologies involved in the development of virtual environments and serious games immersed with medical image and video content. Once the student has completed this module, he/she will be able to analyze problems in the medical domain, extract the needs and requirements and proceed with the design, development, and implementation of the virtual environment of serious game needed. Here the focus is on medical image and video analysis with lab support which is based on freeware software.

After taking this course the students will have a basic understanding in the following areas: Knowledge of basic principles for medical imaging based using advanced image modalities: MRI, CT, Ultrasound and PET-CT; Knowledge of data analysis, image processing and post processing techniques for the different modalities; Knowledge of technological similarities and differences between the different modalities and choice of equipment for different clinical applications; Knowledge of ionizing radiation related risks and radiation protection principles in medical imaging; Knowledge of new applications and technology trends for the different modalities; Knowledge on virtual environments and advanced computer graphics; Game design, fundamentals of gamification, serious games and gamifications for health examples, Serious games design process and game development tools; Knowledge on how to analyze and assess a scientific article.

Below you can find the table of contents of this course:

Part I.1 Medical Imaging. Introduction.

Chapter I. Introduction to medical imaging modalities

Chapter II. Introduction to image and video processing and analysis

Chapter III. Examples from medical applications.

Part I.2 Medical Image Processing

Chapter IV. Binary image processing \& point operations

Chapter V. Fourier Transform

Chapter VI. Linear image filtering

Chapter VII. Non-Linear image filtering

Chapter VIII. Case studies

Part I.3 Medical Image Analysis

Chapter IX. Image quality analysis \& evaluation metrics

Chapter X. Medical image segmentation \& Analysis

Part II. Virtual Environments \& advanced computer Graphics

Chapter XI. Virtual Reality \& computer graphics introduction

Chapter XII. Rendering

Chapter XIII. Interaction

Chapter XIV. Animation

Part III. Game design

Chapter XV. Fundamentals of Gamification

Chapter XVI. Serious games and gamifications for health examples

Chapter XVII. Serious games design process

Chapter XVIII. Games development tools

The assessments considered to this course would be in form of labs and work that could be done at home. They cover group projects work to develop image/video software processing systems.

\subsection{Intensive study programs.}

Three intensive study programs have been designed for IT and health science undergraduate and postgraduate students from the partner institutions. The format of them is a 15 days summer school.

The interdisciplinarity context is a challenge and force to look for different learning-teaching approaches. Summer Schools are also used as a testbed of the eHealth learning materials (described in section 2.1) and innovative teaching methodologies (see section 2.3.1). 


\subsection{1 $1^{\text {st }}$ Summer School: Innovation and Entrepreneurship in eHealth}

It took place in Castres, France, July 2017 and was organized by ISIS Engineering School and collocated with the "Université d'été de la santé" that takes place every July in Castres. The participants were 42 students of the academic institutions of the consortium and 7 professors.

The main objectives of this summer school were fostering team work potential in an international framework, gaining entrepreneurship skills for business creation and allowing students to test their entrepreneurial potential by demonstrating the feasibility of projects and establishing business plans.

The main topics covered were prioritizing competing ideas in teamwork, projecting team building, marketing study, assessment of the market potential, technical validation of products and services, financial aspects and business plan, presentation of a project to an expert board, privacy and data security and ethical and juridical issues, among others.

The Summer School programme promoted learning by doing and will place the student as an actor of his/her own project. In addition to competence gained through courses and workshops on entrepreneurial skills, this approach aims at improving the students' performance through concrete actions carried out within a project team.

Moreover, this summer school served to validate the course Innovation and Entrepreneurship (see section 2.1.1)

\subsection{2 $2^{\text {nd }}$ Summer School: IT for Longer Independent Life}

It took place in Wrexham, Wales, UK, July 2018 and was organized by Wrexham Glyndwr University. The participants were 47 students of the academic institutions of the consortium and 13 professors.

The main topics covered were overview of health issues that can affect independent living, principles of Human-Computer Interaction understanding user populations, especially older people, user interface design tools and practice, user interface evaluation and designing for older and disabled people, among others.

Moreover, this summer school served to validate the courses 2 (IT for a Longer Independent Life) and 3 (eHealth Applications and Tools). See sections 2.1.2 and 2.1.3 for more information on these courses.

Further information on this summer school could be found in [8].

\subsection{3 $3^{\text {rd }}$ Summer School: IT for Physical and Cognitive Desabilities}

It is taking place in Barcelona, Spain, July 2019 and is organized by Universitat Politècnica de Catalunya-BarcelonaTech. There are attending this summer school 63 students from the academic institutions of the consortium and 11 professors.

This summer school lay special emphasis on eHealth solutions for physical and cognitive disabilities. It will bring together IT and Health students that will develop and test solutions related to robotics, graphics, serious games, virtual reality and medical imaging. Learners will attend practical sessions in medical robotics labs and will go on visits to several research centers.

The objectives of this summer school are: considering human factors as part of the inputs to a project to be developed, analysing a problem and identifying the project requirements, selecting the adequate control strategy for each robot project, acquiring basic know-how on technologies involved in the development of virtual environments and serious games, and designing, developing and implementing suitable virtual environment and serious games.

Consequently, the main topics covered during the summer school are: human robot interaction in medical robotics, assistive and rehabilitation robotics, improving cognitive and communication skills and serious games and game based learning, among others.

Moreover, this summer school served to validate the courses 4 (Robotics for Healthcare) and 5 (Graphics and Medical Imaging). See sections 2.1.4 and 2.1.5 for more information on these courses.

Tables 1 and 2 show the distribution of the students and professors per institution, respectively. 
Table 1. Students in the summer schools per institution.

\begin{tabular}{l|c|c|c|c|c|c|c|c}
\hline \hline & UPC & UIB & ISIS & UM & WGU & HSU & UCY & FSJD \\
\hline $1^{\text {st }}$ Summer School & 5 & 8 & 3 & 5 & 3 & 5 & 8 & 5 \\
\hline $2^{\text {nd }}$ Summer School & 6 & 11 & 6 & 0 & 3 & 6 & 10 & 5 \\
\hline $3^{\text {rd }}$ Summer School & 7 & 13 & 7 & 7 & 5 & 7 & 10 & 7 \\
\hline \hline
\end{tabular}

Table 2. Professors in the summer schools per institution.

\begin{tabular}{l|c|c|c|c|c|c|c|c}
\hline \hline & UPC & UIB & ISIS & UM & WGU & HSU & UCY & FSJD \\
\hline $1^{\text {st }}$ Summer School & 1 & 1 & 1 & 1 & 1 & 0 & 1 & 1 \\
\hline $2^{\text {nd }}$ Summer School & 0 & 3 & 0 & 1 & 3 & 3 & 1 & 2 \\
\hline $3^{\text {rd }}$ Summer School & 1 & 3 & 1 & 1 & 1 & 1 & 1 & 2 \\
\hline \hline
\end{tabular}

\subsection{Training seminars}

Two training seminars have been designed for professors and researchers of the IT and Health Science fields. One of them focused in teaching challenges in eHealth and the other one in accessibility, inclusion and rehabilitation using IT.

Tables 3 shows the distribution of the participants per institution.

Table 3. Participants in the training seminars per institution.

\begin{tabular}{l|c|c|c|c|c|c|c|c|c}
\hline \hline & UPC & UIB & ISIS & UM & WGU & HSU & UCY & FBIT & FSJD \\
\hline $1^{\text {st }}$ Training Seminar & 2 & 3 & 0 & 2 & 3 & 2 & 0 & 0 & 2 \\
\hline $2^{\text {nd }}$ Training Seminar & 3 & 5 & 0 & 0 & 2 & 4 & 2 & 4 & 3 \\
\hline \hline
\end{tabular}

\subsection{1 $1^{\text {st }}$ Training Seminar: eHealth Teaching Challenges}

It took place in Montpellier, France, in October 2017 and was organized by University of Montpellier. Fourteen researches and professors from the partners of the consortium attended the training seminar.

The seminar consisted essentially of a mix of lectures, workshops, and exercises, through which participants were encouraged to use the developed course modules on their own learning activities. The seminar was animated by engineers and experts in pedagogical innovation.

The challenges to be faced when teaching eHealth are: teach a big number of students, coming from different backgrounds (health, engineering, IT,...), as it is the case in running the described summer schools (section 2.2), take into account the need of each student, adapt the courses to the new generations, use the technology as we used the pencil and blackboard.

The objective of this seminar was exchanging the teaching experience of the Information and Communication Technology (ICT) modules with the partner members in the objective of improving the teaching in the field of ICT for Health.

\subsection{2 $2^{\text {nd }}$ Training Seminar: Accessibility, inclusion and rehabilitation using IT}

It took place in Palma de Mallorca, Spain, in November 2018 and was organized by University of Balearic Islands. Twenty-three researches and professors from the partners of the consortium attended the training seminar.

The main objective of this seminar was to establish an open exchange dedicated to the presentation and discussion about accessibility, inclusion and rehabilitation using Information Technologies.

In this context Information Technologies refers to the development, maintenance, and use of computer systems, software, and networks for the processing and distribution of data specific to the community or individual in relation to issues of accessibility, inclusion and/or rehabilitation. 
Attendees were encouraged to present their specific research that aligns with the general framework of the topic of this training seminar, such as prevention, diagnosis, therapy, rehabilitation, long-term care, or telemedicine.

Some topics of the seminar were IT for rehabilitation, robotics on eHealth, assisted living technologies, practical applications of eHealth, image and video processing on eHealth, eHealth for public health and eHealth for aging, IT for the inclusion for people with different abilities and preferences, design, evaluation, and use of IT to benefit people with disabilities and elderly people, information technologies to accessibility to enable people with functional limitation to perform tasks that they were formerly unable to accomplish.

\section{CONCLUSIONS}

The consortium of the eHealth Eurocampus project along with the participants of the designed activities have created an original eHealth teaching-learning framework where university professors, students, researchers, and clinicians are able to share their experiences and knowledge with the aim of improving the skills of graduates in order to improve their employability.

We believe this is the first approach to a teaching-learning framework specifically designed for students of both healthcare and technology, with a view to creating hybrid eHealth professionals of the future.

The five modules of 6 ECTS each will be available for public use from the web page of the eHealth Eurocampus project at the end of 2019.

\section{ACKNOWLEDGEMENTS}

This project is carried out with the financial support from EU commission under the Erasmus+ Program, KA2 - Cooperation for Innovation and the Exchange of Good Practices, Strategic Partnership for higher education (ref. 2016-1-FR01-KA203-023932). The authors also want to thank the participants (students, teachers and administrators) of the eHealth Eurocampus project.

\section{REFERENCES}

[1] N. Castell et al., "EHEALTH EUROCAMPUS PROJECT: PREPARING INNOVATIVE ICT PROFESSIONALS," INTED2019 Proc., pp. 5560-5564, 2019.

[2] G. Eysenbach, "What is e-health?," J. Med. Internet Res., vol. 3, no. 2, p. E20, 2001.

[3] V. Della Mea, "What is e-health (2): the death of telemedicine?," J. Med. Internet Res., vol. 3, no. 2, p. E22, Jun. 2001.

[4] T. Shaw, D. McGregor, M. Brunner, M. Keep, A. Janssen, and S. Barnet, "What is eHealth (6)? Development of a Conceptual Model for eHealth: Qualitative Study with Key Informants.," J. Med. Internet Res., vol. 19, no. 10, p. e324, Oct. 2017.

[5] M. H. van Velthoven, C. Cordon, and G. Challagalla, "Digitization of healthcare organizations: The digital health landscape and information theory," Int. J. Med. Inform., vol. 124, pp. 49-57, Apr. 2019.

[6] C. O'Connor, Yvonne; Heavin, "Defining and Characterizing the Landscape of E-Health in 'Advanced Methodologies and Technologies in Medicine and Healthcare,"' M. Khosrow-Pour, D.B.A., Ed. IGI Global, 2019.

[7] Conference of the French University Presidents, "Université et entrepreneuriat étudiant Guide pratique GUIDE RÉALISÉ AVEC LE CONCOURS," 2016.

[8] R. Picking, A. G. Sans, E. I. Calderon, and I. S. Bueno, "AN EVALUATION OF STUDENT PERCEPTIONS OF THE EFFECTIVENESS OF MULTIDISCIPLINARY TEACHING AND LEARNING IN EHEALTH," INTED2019 Proc., pp. 5652-5658, 2019. 